\title{
Siirt Bölgesi Melengiçlerin Toplam Fenolik Madde Miktarları ve Antioksidan Aktivitelerinin Belirlenmesi
}

\author{
Cemhan DOĞAN ${ }^{1^{*}}$, Şerafettin ÇELiK ${ }^{2}$, Nurcan DOĞAN ${ }^{1}$ \\ ${ }^{1}$ Bozok Üniversitesi, Boğazlıyan Meslek Yüksekokulu, Gıda Iş̧leme Bölümü, YOZGAT \\ [ORCID ID: orcid.org/0000-0002-9043-0949 (C. DOĞAN), 0000-0001-5414-1819 (N. DOĞAN)] \\ ${ }^{2}$ Harran Üniversitesi, Ziraat Fakültesi, Gıda Mühendisliği Bölümü, ŞANLIURFA \\ [ORCID ID: http://orcid.org/0000-0002-5605-5735] \\ *Sorumlu yazar: cemhandogan@hotmail.com
}

Öz

Bu çalışmada Melengiç meyvesi su, etanol ve metanolle ekstrakte edilmiş ve daha sonra ekstraktların toplam fenolik madde miktarları ve antioksidan aktiviteleri (DPPH ve İndirgeyici güç) belirlenmiştir. Buna göre, Melengiç meyvesinin biyoaktivitesi yüksek bir materyal olduğu sonucuna varılmıştır. Ayrıca, etanol ve metanolden elde edilen ekstraktların sudan elde edilen ekstraktlara göre daha yüksek fenolik madde içeriğine ve antioksidan aktiviteye sahip olduğu gözlemlenmiştir.

Anahtar Kelimeler: Melengiç, Antioksidan aktivite, Fenolik madde

\section{Determination of Total Phenolic Compound Amounts and Antioxidant Activities of Siirt Region Melengic}

\section{Abstract}

In this study Melengic was extracted by water, ethanol and methanol and than total phenolic content and antioxidant activity (DPPH and reducing power) of these extracts were determined. According to the results, it was concluded that Melengic is a material with a high bioactivity. On the other hand, ethanol and methanol extracts were found to have higher phenolic content and antioxidant activity than the water extract.

Key Words: Melengic, Antioxidant activity, Phenolic compounds

\section{Giriş}

Melengiç kuvvetli reçine kokulu küçük bir ağaçtır. Anacardiaceae (Sakız ağacıgiller, antepfıstığıgiller) familyasının bir üyesi olan bu ağaç türü Asya ve Akdeniz'e özgü bir bitki olmakla birlikte, ülkemizde yaygın olarak Güney kesimlerde yetişir (Davis, 1970). Özellikle Toros dağlarındaki çam ormanlarında 1600 m yükseklikte yetişmekle birlikte, Doğu Anadolu ve Güneydoğu Anadolu bölgelerinin kırsal kesimlerinde de yaygın olarak yetiştiği bilinmektedir.
Melengiç meyvesi küçük, küre biçiminde olup olgunlaşınca rengi yeşilden maviye dönüşmektedir. Tohumları ağustos-eylül döneminde olgunlaşmaktadır. Soğuğa ve kuraklığa karşı dayanıklı olan bu ağaç türü drenajı iyi, kuru, sıcak, kireçli ve kayalık alanlarda daha iyi yetişmektedir. En iyi gelişmeyi alkali topraklarda göstermektedir ve bununla birlikte bu bitkinin büyüme hızı düşük, ışık isteği oldukça yüksektir (Çiftci ve ark., 2009). Melengiç, ülkemizin doğal bitki örtüsünün bir parçası olup, tarımı yapılmaksızın doğal olarak kendiliğinden 
yetişen bir bitkidir ve aynı zamanda aşılanmak sureti ile antepfıstığına dönüştürülebilmektedir. Ülkemizdeki antepfıstığı ağacı sayısı 42 milyon olup bunun 14 milyon kadarı Melengiç gibi yabani türlerin aşılanması sureti ile elde edilmiştir. Melengiç bitkisinin aromatikliği ve ilkel zamanlardan beri bilinen tıbbi özellikleri, tanen (polifenolik bileşikler) ve reçine maddelerince zengin bir bitki olmasından kaynaklanmaktadır. Bitkinin genç sürgün ve meyveleri gıda olarak kullanılabilmektedir. Melengiç meyveleri ülkemizde özel köy ekmeklerinin yapımında ve meze olarak kullanılmaktadır. Melengiç meyveleri halk hekimliğinde, romatizma, öksürük ve karın ağrısı tedavisinde kullanıldığı gibi, yaprakları kaynatılarak mide tedavisinde de kullanılmaktadır (Stebbins ve Walheim, 1981; Baytop, 1984; Duke, 2002). Melengiç tohumlarının kavrulması sureti ile hazırlanan ve çedene kahvesi (Melengiç kahvesi) olarak bilinen içeceğin halk hekimliğinde balgam söktürücü, solunum ve idrar yolları antiseptiği, göğüs yumuşatıcl, vücut içindeki yaraları tedavi edici, ayak terlemelerini önleyici, kolesterol düşürücü ya da önleyici, regl söktürücü ve böbrek kumlarının dökülmesine yardımcı olması gibi bir takım özelliklerinin olduğu da bilinmektedir (Ciftçi ve ark., 2009). Birçok faydalı etkisi olan bu bitkinin bazı biyoakif özellikleri özellikle son yıllarda yapılan in-vivo çalışmalarda ortaya konmuştur ( Topçu ve ark., 2007; Kaçar, 2008; Kavak ve ark, 2010; Durmaz ve Gökmen, 2011; Orhan ve ark., 2012). Yapılan bu çalışmada, Siirt ilinden toplanan Melengiç meyvelerinin su, etanol ve metanol ekstraktlarının toplam fenolik madde miktarları ve iki farklı metotla (DPPH ve Indirgeme gücü) antioksidan aktiviteleri ortaya konmuştur.

\section{Materyal ve Metot}

Materyal

Melengiç örnekleri Siirt ili Eruh ilçesinden 2013 yılı ekim ayında toplanmıştır. Toplanan örnekler oda şartlarında, güneş görmeyecek şekilde ince bir tabaka halinde serilerek kurutulmuştur. Daha sonra örnekler değirmende çekilerek $-18{ }^{\circ} \mathrm{C}^{\prime}$ de kullanılacak zamana kadar depolanmıştır.

\section{Örneklerin ekstraksiyonu}

Örneklerin ekstraksiyonunda Kavak ve ark. (2010)'nın uyguladıkları soğuk ekstraksiyon metodu modifiye edilerek kullanılmıştır. Su ile yapılan ekstraksiyonlarda $10 \mathrm{~g}$ örnek tartılmış ve üzerine $100 \mathrm{ml}$ su eklenmiştir. Daha sonra çalkalamalı su banyosunda $60{ }^{\circ} \mathrm{C}$ 'de 12 saat bekletildikten sonra önce kaba filtre sonra da whatman 4 filtre kağıdından geçirilen örnekler santrifüjlenerek süpernatant alınmış ve stok çözelti olarak kullanılmıştır. Çözgen olarak etanol ve metanol kullanılan ekstraktların elde edilmesinde $10 \mathrm{~g}$ örnek tartılmış $90 \mathrm{ml}$ çözgen, $10 \mathrm{ml}$ su ilave edilmiştir (Ön çalışmalar sonucunda rotary evaporatörde saf ekstrakt eldesi sırasında yapışma gözlendiği için çözgene \%10 su ilave edilmiştir). Daha sonra ağzı kapalı parafilmlenmiş şekilde beherler içinde çalkalamalı su banyosunda $50{ }^{\circ} \mathrm{C}^{\prime}$ de 12 saat bekletildikten sonra önce kaba filtre sonra da whatman 4 filtre kâğıdından geçirilen örnekler satrifüjlenerek süpernatant alınmış ve son olarak rotary evaporatörde kullanılan çözgene göre etanol yada metanol uzaklaşana kadar vakum altında bekletilmiştir. Elde edilen ekstrakt-su karışımı stok çözelti olarak kullanılmıştır. 


\section{Toplam Fenolik Madde Miktarı}

Kabuk ekstraktların toplam fenolik madde miktarları, Folin-Ciocalteu (FCR, $\mathrm{Na}_{2} \mathrm{MoO}_{4}$ $\left.+\mathrm{Na}_{2} \mathrm{WO}_{4}+\mathrm{H}_{3} \mathrm{PO}_{4}\right)$ reaktifi ile Slinkard and Singleton (1977) 'un belirttiği metoda göre belirlenmiştir. Bu amaçla her bir ekstraktan ayrı ayrı $100 \mu \mathrm{L}(0.1 \mathrm{~mL})$ alınarak $50 \mathrm{~mL}$ lik balon jojelerin her birine bırakıldıktan sonra buna $46 \mathrm{~mL}$ deiyonize su ilave edilmiştir. Daha sonra $1 \mathrm{~mL}$ FCR eklenmiş ve 3 dakika beklenmiştir. Son olarak $3 \mathrm{~mL} \% 2^{\prime}$ lik $\mathrm{Na}_{2} \mathrm{CO}_{3}$ ilavesi yapılmış ve karışım 2 saat bekletildikten sonra $760 \mathrm{~nm}$ 'de absorbanslar okunmuştur. Kör numune, $1 \mathrm{~mL} F C R$ üzerine, $3 \mathrm{~mL} \% 2^{\prime}$ 'lik $\mathrm{Na}_{2} \mathrm{CO}_{3}$ eklenmiş ve $50 \mathrm{~mL}$ 'ye kadar distile su ile seyreltilerek hazırlanmıştır. Standardın ise (gallik asit) 0.05 mg.mL ${ }^{-1}, 0.1$ mg.mL ${ }^{-1}, 0.25$ mg.mL ${ }^{-1}, 0.5$ $\mathrm{mg} \cdot \mathrm{mL}^{-1}$ ve 1 mg.mL ${ }^{-1}$ lik çözeltileri hazırlanmıştır. Ortamda fenolik maddenin bulunması durumunda FCR ilavesiyle 760 $\mathrm{nm}$ 'de maksimum absorbans veren ürünler oluşmaktadır. Absorbanstaki artış fenolik madde miktarıyla orantılıdır. Seyreltilmiş ekstrakttaki fenolik madde miktar tayini standart gallik asit grafiğinden elde edilen oranlarla gallik asit eş değeri olarak aşağıdaki formüle göre hesaplanmıştır.

Absorbans $=0.001 \times$ Total fenol [gallik asit eş değeri $(\mu \mathrm{g})]-0.0154$

$D P P H$ serbest radikali söndürme aktivite testi

Melengiçten elde edilen ekstraktların DPPH radikali söndürme aktivitesi Blois (1958)'in rapor ettiği metoda göre yapılmıştır. Bu deneyde her bir tüpe $0.1 \mathrm{mM}$ $\mathrm{DPPH}^{\prime}$ In metanol çözeltisinden $1 \mathrm{~mL}$ alınarak, daha önce $3 \mathrm{~mL}$ olarak farklı konsantrasyonlarda hazırlanmış (1-10 mg. $\mathrm{mL}^{-}$ $\left.{ }^{1}\right)$ örnek ekstraklarını içeren tüplere ilave edilmiştir. Çözelti vorteksde karıştırııı ışık görmeyecek şekilde karanlık bir ortamda 30 dk. süreyle oda sıcaklığında inkübasyona bırakıldıktan sonra $517 \mathrm{~nm}$ 'de absorbanslar ölçülmüştür. Kör olarak kullanılan çözeltiye sadece $4 \mathrm{~mL}$ metanol eklenerek, kontrol çözeltisi için ise $1 \mathrm{~mL}$ DPPH üzerine $3 \mathrm{~mL}$ metanol ilave edilerek hazırlanmıştır. Hazırlanan DPPH çözeltisi 517 nm'de maksimum absorbans değeri veren koyu mor bir renk oluşturmaktadır. Bu DPPH çözeltisi antioksidan madde veya maddeler içeren bir solüsyona katıldığında bu koyu mor renk zamanla rengini kaybetmeye başlar. Bu da antioksidan maddelerin DPPH radikalini söndürdüğünün kanıtıdır. Bu işlemi de ya ondan hidrojen atomu kopararak ya da ona elektron vererek gerçekleştirir. Böylece onları renksiz ve ağartılmış moleküller haline getirirler (2,2-difenil---hidrazin veya hidrazinin farklı analogları). Bu da 517 nm'de absorbans değerinin azalmasına yol açar. Absorbans değerindeki en hızlı azalma, en iyi antioksidan potansiyelinin göstergesidir. DPPH serbest radikalini söndürme yüzdesi aşağıdaki formüle göre hesaplanmıştır.

Yüzde inhibisyon $=\left(A_{0}-A_{1}\right) / A_{0} \times 100$

$\left(A_{0}\right.$ :Kontrol Absorbans, $A_{1}$ : Numune Absorbans)

Hesaplanan yüzdeler kullanılarak oramdaki DPPH serbest radikalinin \%50'sini süpüren konsantrasyon $\mathrm{EC}_{50}$ değeri olarak verilmiştir $\left(\mathrm{EC}_{50}\right.$ değeri hesaplanırken Microsoft Excel programında hazırlanan lineer regresyon eğrisi kullanılmıştır.)

\section{Indirgeyici güç aktivite testi}

Melengiçten elde edilen ekstraktların indirgeyici güç aktivitelerinin belirlenmesinde Oyaizu (1986)'nun metodu kullanılmıştır. Burada farklı konsantrasyonlarda (1-10 mg/ $\mathrm{mL}$ ) hazırlanan ekstraktlardan $1 \mathrm{~mL}$ alınarak üzerine $2.5 \mathrm{~mL} 200 \mathrm{mM}$ potasyum hidrojen 
fosfat $\left(\mathrm{KH}_{2} \mathrm{PO}_{4}\right)$ tampon (pH: 6.6) ve \%1' lik $2.5 \mathrm{~mL}$ potasyum ferrisiyanür $\left(\mathrm{K}_{3} \mathrm{Fe}(\mathrm{CN})_{6}\right)$ çözeltileri ilave edilerek $50{ }^{\circ} \mathrm{C}$ de 20 dakika etüvde bekletilmiştir. $\mathrm{Bu}$ sürenin sonunda etüvden çıkarılan çözeltiler üzerine $2.5 \mathrm{ml}$ $\% 10$ 'luk TCA ilave edildikten sonra, 200 rpm'de 10 dk santrifüj edilmiştir. Santrifüjlenen çözeltinin süpernatant kısmından $2.5 \mathrm{~mL}$ alınarak üzerine $2.5 \mathrm{~mL}$ distile su ve $0.5 \mathrm{~mL} \% 0.1^{\prime}$ lik $\mathrm{FeCl}_{3}$ (demir III klorür) çözeltisi ilave edilmiştir. Daha sonra UV-Vis spektroskopisinde $700 \quad \mathrm{~nm}$ 'de numunelerin absorbansları ölçülmüştür. Deneyde, kör çözelti; ekstrakt içermeyen 2.5 $\mathrm{mL}$ fosfat tamponu üzerine $2.5 \mathrm{~mL} \mathrm{~K}{ }_{3} \mathrm{Fe}(\mathrm{CN})_{6}$ eklenerek 20 dakika $50{ }^{\circ} \mathrm{C}$ 'de bekletilmiş daha sonra bu çözeltinin üzerine $2.5 \mathrm{~mL}$ TCA eklenerek, bu karışımdan $1 \mathrm{~mL}$ alınmış ve alınan bu çözelti üzerine $1 \mathrm{~mL} \mathrm{FeCl}{ }_{3}$ ilave edilerek hazırlanmıştır. Başlangıçta oluşan $\left(\mathrm{Fe}^{3+}\right)$ ferrisiyanid kompleksi sarı renkte bir solüsyon oluşumuna neden olmaktadır. Ortamdaki antioksidanlar, ferrisiyanid kompleksine elektron vererek, bu bileşiği indirgemekte ve böylece $\left(\mathrm{Fe}^{2+}\right)$ ferrosiyanür oluşumuna neden olarak, solüsyonun renginin yeşil ve mavinin farklı tonlarına dönüşmesine yol açarak $700 \quad \mathrm{~nm}$ 'de maksimum absorbans vermesini sağlamaktadır. Ortamdaki antioksidanların indirgeyici güçlerine bağlı olarak, 700 nm'deki absorbans değerinin artması ekstraktların indirgeyici gücünün göstergesi olarak kabul edilmiştir.

\section{Istatistiki analizler}

Çalışmaya ait veriler, çift yönlü ANOVA ile analiz edilmiş, önemli bulunan ortalamalar arasındaki farklılık Tukey çoklu karşılaştırma testi ile belirlenmiştir. Varyans analizi ve Tukey çoklu karşılaştırma testi için SPSS 22.0 istatistik paket programı kullanılmıştır.

\section{Araştırma Bulguları ve Tartışma}

\section{Toplam Fenolik Madde Miktarı Sonuçları}

Melengiç'den farklı solventlerle elde edilen ekstraktların Folin Ciocalteu metoduna göre yapılan analizinde toplam fenolik madde miktarları mg Gallik asit eşdeğeri/g ekstrakt cinsinden Çizelge 1'de verilmiştir. Değerler ekstraksiyonda kullanılan solventler açısından incelendiğinde istatistiksel olarak farklılıklar tespit edilmiştir. Örneklerin fenolik madde miktarında yüksek etkinlikten düşük etkinliğe göre sıralama metanol, etanol ve su şeklinde olmuştur.

Çizelge 1. Ekstraktlara ait ortalama toplam fenolik madde miktarları (mg GAE/g ekstrakt) Table 1. The average total amount of phenolic compounds in extracts (mg GAE/g extract)

\begin{tabular}{|c|c|c|c|}
\hline & $\mathrm{Su}$ & Etanol & Metanol \\
\hline & Water & Ethanol & Methanol \\
\hline Melengiç & $16.12 \pm 1.14^{A^{*}}$ & $36.19 \pm 2.92^{B}$ & $43.81 \pm 6.12^{C}$ \\
\hline
\end{tabular}

Melengiç örneklerinin belirlenen toplam fenolik madde miktarı değerleri Topçu ve ark. (2007), Kaçar (2008) ve Orhan ve ark. (2012)'nın yaptıkları çalışmadan düşük, Kavak ve ark. (2010) çalışma ile uyumlu, Durmaz ve Gökmen (2011)'in yaptıkları çalışmadan ise yüksek olarak tespit edilmiştir.

DPPH Serbest Radikali Söndürme Aktivitesi Sonuçları

Örneklerden elde edilen ekstraktların DPPH serbest radikalini söndürme 
aktivitelerinin belirlenmesi sonucu elde edilen \% söndürme aktivitesi lineer regresyon analizine tabi tutularak $\mathrm{EC}_{50}$ değeri hesaplanmıştır. Buna göre yapılan analizde ortaya çıkan $\mathrm{EC}_{50}$ değerleri $\mathrm{mg}$ ekstrakt / $\mathrm{mL}$ cinsinden Çizelge 2'de verilmiştir. DPPH radikalinin yarısının ortamdan süpürülmesi için gerekli olan konsantrasyon yoğunluğu $\mathrm{EC}_{50}$ değeri olarak ifade edilmektedir. $\mathrm{EC}_{50}$ değerinin düşük olması örneğin antioksidan aktivitesinin yüksek olduğunu, yüksek olması ise örneğin antioksidan aktivitesinin düşük olduğunu göstermektedir (Aqil ve ark., 2006).

Çizelge 2. Ekstraktlara ait ortalama DPPH EC $\mathrm{C}_{50}$ değerleri (mg ekstrakt $/ \mathrm{mL}$ )

Table 2. The average DPPH EC 50 values of extracts

\begin{tabular}{|c|c|c|c|}
\hline & $\begin{array}{l}\text { Su } \\
\text { Water }\end{array}$ & $\begin{array}{l}\text { Etanol } \\
\text { Ethanol }\end{array}$ & $\begin{array}{l}\text { Metanol } \\
\text { Methanol }\end{array}$ \\
\hline Melengiç & $3.49 \pm 0.16^{B^{*}}$ & $4.11 \pm 0.48^{C}$ & $2.61 \pm 0.21^{A}$ \\
\hline
\end{tabular}

Değerler kullanılan solvent bakımından incelendiğinde üç farklı grubun oluştuğu gözlenmiş̧ir. Sonuçlar incelendiğinde antioksidan kapasite açısından metanolün diğer solventlere kıyasla daha iyi bir ekstraktsiyon solventi olduğu sonucuna varılmıştır.

\section{Indirgeyici Güç Kapasitesi Sonuçları}

Örneklerden elde edilen ekstraktların ferrisiyanid kompleksini indirgeme güçlerinin belirlenmesi için yapılan spektral analiz sonucu absorbans değerleri ortaya çıkmıştır. Elde edilen absorbans değerleri ve konsantrasyon ilişkisi lineer regresyon analizine tabi tutulup 0.5 absorbansı veren konsantrasyon $\mathrm{EC}_{50}$ değeri olarak ifade edilmiştir. Buna göre yapılan analizde ortaya çıkan $\mathrm{EC}_{50}$ değerleri mg ekstrakt/ml cinsinden Çizelge 3'de verilmiştir.

Çizelge 3. Ekstraktlara ait ortalama ait indirgeyici güç $\mathrm{EC}_{50}$ değerleri (mg ekstrakt $/ \mathrm{mL}$ )

Table 3. The average reducing power $E C_{50}$ values of extracts

\begin{tabular}{clll}
\hline & Su & Etanol & Metanol \\
& Water & Ethanol & Methanol \\
\hline Melengiç & $14.16 \pm 2.79^{\mathrm{C}^{*}}$ & $8.59 \pm 1.63^{\mathrm{B}}$ & $5.54 \pm 0.61^{\mathrm{A}}$ \\
\hline${ }^{*}$ Farklı harflerle ifade edilen değerler arasındaki fark istatistiki olarak \%5 düzeyinde önemlidir
\end{tabular}

Çalışmada kullanılan örneklerin göstermiş olduğu indirgeyici güç aktivitesi, bunların içerdiği redüktanlarla ilişkili olabilmektedir. Redüktanlar serbest radikallere hidrojen atomu vermek suretiyle reaksiyona girerek radikal zincir reaksiyonlarını sonlandırmakta ve dolayısıyla serbest radikal zincirlerin kırılmasına yol açarak antioksidan aktivite sergilemektedirler (Ferreira ve ark., 2007). Örneklerin indirgeyici güç kapasitelerinin hidrojen verebilme kabiliyetlerine bağı olduğu, bunun da redüktan içeriğiyle doğru orantılı olduğu belirtilmektedir (Yang ve ark. 2002). Değerler incelendiğinde istatistiksel olarak farklılıklar tespit edilmiştir. Solventlerin indirgeme gücüne etki potansiyelleri kıyasladığında en yüksek potansiyelin metanolde, sonra etanolde daha sonra da suda olduğu tespit edilmiştir. 


\section{Sonuçlar}

Sonuç olarak ülkemizde yetişen Melengiç meyvesinin fenolik madde miktarları ve antioksidan özellikleri incelendiğinde örneklerde önemli oranlarda biyoaktivite potansiyelinin olduğu gözlemlenmiştir. En yüksek ekstraksiyon verimliliği her ne kadar su ile elde edilmiş olsa da sulu ekstrakt diğer solventlere nazaran daha düşük antioksidan aktivite göstermiştir. Elde edilen sonuçlar Melengiç meyvesinin fonksiyonel ürünlerin üretiminde kullanılabilecek önemli bir kaynak olabileceğini göstermiştir. Bu potansiyel, ekstraksiyon işlemi ve verimliliğini optimize etmek amacı ile sıcaklık, zaman, basınç ve bazı özel şartlar üzerine yapılacak yeni çalışmalarla arttırılabilir.

\section{Ekler}

Bu makale, Harran Üniversitesi Bilimsel Araştırma Projeleri Birimi (HÜBAK) tarafından 14046 kodlu proje ile desteklenen tez çalışmasından elde edilen sonuçlarla oluşturulmuştur. Değerli destekleri için HÜBAK'a teşekkür ederiz.

\section{Kaynaklar}

Aqil, F., Ahmad, I., Mehmood, Z., 2006. Antioxidant and free radical scavenging properties of twelve traditionally used Indian medicinal plants. Turkish journal of Biology, 30(3), 177-183.

Baytop, T., 1984. Türkiye' de Bitkiler ile Tedavi. İstanbul Üniversitesi Yayınları.No: 3235Eczacılık Fakültesi. No:40, İstanbul.

Blois, M. S., 2002,. Antioxidant determinations by the use of a stable free radical. Nature, 26:1199-1200.

Ciftci, H., Ozkaya, A., Kariptas, E., 2009. Determination of fatty acids, vitamins and trace elements in Pistacia terebinthus coffee. Journal of Food Agriculture Environment, 7(3-4): 72-74.
Davis, P. H., 1970. Flora of Turkey and the East Aegean Islands. Vol. 3. Flora of Turkey and the East Aegean Islands. Vol. 3.

Duke, J. A., 2002. CRC Handbook of medicinal spices: CRC press.

Durmaz, G., Gökmen, V., 2011. Changes in oxidative stability, antioxidant capacity and phytochemical composition of Pistacia terebinthus oil with roasting. Food Chemistry, 128(2): 410-414.

Ferreira, I. C., Baptista, P., Vilas-Boas, M., Barros, L., 2007. Free-radical scavenging capacity and reducing power of wild edible mushrooms from northeast Portugal: Individual cap and stipe activity. Food Chemistry, 100(4): 1511-1516.

Kaçar, D., 2008. Screening of some plant species for their total antioxidant and antimicrobial activities. Izmir Institute of Technology, Department of Biotechnology and Bioengineering, Izmir, p. 54.

Kavak, D. D., Altıok, E., Bayraktar, O., Ülkü, S. 2010. Pistacia terebinthus extract: As a potential antioxidant, antimicrobial and possible $\beta$-glucuronidase inhibitor. Journal of Molecular Catalysis B: Enzymatic, 64(3), 167-171.

Orhan, I. E., Senol, F. S., Gulpinar, A. R., Sekeroglu, N., Kartal, M., Sener, B., 2012. Neuroprotective potential of some terebinth coffee brands and the unprocessed fruits of Pistacia terebinthus L. and their fatty and essential oil analyses. Food Chemistry, 130(4), 882-888.

Oyaizu, M., 1986. Studies on products of browning reaction--antioxidative activities of products of browning reaction prepared from glucosamine. Eiyogaku zasshi= Japanese journal of nutrition, 14(1): 51-58

Slinkard, K., Singleton, V. L., 1977. Total phenol analysis: automation and comparison with manual methods. American Journal of Enology and Viticulture, 28(1), 49-55.

Stebbins, R. L., Walheim, L., 1981. Western fruit, berries \& nuts: HP Books.

Topçu, G., Ay, M., Bilici, A., Sarıkürkcü, C., Öztürk, M., Ulubelen, A., 2007. A new flavone from antioxidant extracts of Pistacia terebinthus. Food Chemistry, 103(3), 816822.

Yang, J. H., Lin, H. C., Mau, J. L., 2002. Antioxidant properties of several commercial mushrooms. Food Chemistry, 77(2): 229235. 